\title{
Assessing Adoption Levels of Electronic Billing by Lusaka Water Supply and Sanitation Company
}

\author{
Exildah Twaambo', Jackson Phiri ${ }^{2}$ \\ ${ }^{1}$ Graduate School of Business, University of Zambia, Lusaka, Zambia \\ ${ }^{2}$ Department of Computer Science, School of Natural Sciences, University of Zambia, Lusaka, Zambia \\ Email: etwaambo@gmail.com, Jackson.phiri@cs.unza.zm
}

How to cite this paper: Twaambo, E., \& Phiri, J. (2022). Assessing Adoption Levels of Electronic Billing by Lusaka Water Supply and Sanitation Company. Open Journal of Business and Management, 10, 564-576.

https://doi.org/10.4236/ojbm.2022.101031

Received: October 30, 2021

Accepted: January 27, 2022

Published: January 30, 2022

Copyright $\odot 2022$ by author(s) and Scientific Research Publishing Inc. This work is licensed under the Creative Commons Attribution International License (CC BY 4.0).

http://creativecommons.org/licenses/by/4.0/

(c) (i) Open Access

\begin{abstract}
The purpose of this study was to assess the adoption levels of e-billing at Lusaka Water Supply and Sanitation Company (LWSSC). The objectives of the study were to establish the benefits of the adopted e-billing system by LWSSC and to identify factors affecting adoption levels of E-billing at Lusaka Water Supply and Sanitation Company (LWSSC) based on the UTAUT model. The study employed a mixed methods design known as an embedded design. The total population for this study was 80,125 customers and the sample size was 398. The questionnaires were distributed to 398 customers and 298 responded giving the response rate of $72 \%$. Quantitative data was obtained from the questionnaires while qualitative data was obtained for the interviewed key informants who are LWSC employees. Customers were sampled using stratified random sampling while purposive sampling was used on key informants for interviews. The results showed that there is significant relationship between effort expectancy (ease of use/levels of education) and adoption of e-billing as it had a $p$-value of 0.03 . The result further showed that facilitating conditions (accessibility to internet) had an impact on the adoption of e-billing by customers. An observed $p$ value of 0.021 was observed against the significant level of 0.05 . The chi square test also showed that social influence (sensitization) affected adoption levels of e-billing which had a $p$-value of 0.021 . It was therefore concluded that education, access to internet/phones and sensitization had a significant relationship with adoption of e-billing.
\end{abstract}

\section{Keywords}

Electronic Billing, Adoption, UTAUT Model 


\section{Introduction}

Lusaka Water Supply and Sanitation Company (LWSSC) is a utility company mandated to provide water and sanitation services in Lusaka Province. Being a quasi-government institution, its operations are sustained by revenue collected from water sales to both domestic and commercial customers. The need to improve revenue collection has prompted the company to find innovative ways to improve business processes that cannot only lower.

Operational costs can improve collection efficiency and service delivery. Evidently, most water utility companies globally are taking advantage of technology advancements to find innovative ways of enhancing timely bill delivery, revenue collection and operational efficiency hence the introduction of electronic billing. Poel et al. (2016) affirm that implementing electronic invoicing is expected to have a significant impact on the processes and transaction costs (thus the costs associated with business operations). Sakala and Phiri (2019) also revealed that the utilities surveyed experienced several benefits of incorporating Information and Communication Technology (ICT) in their operations.

E-billing is part of the electronic commerce that has advanced the way companies interact with their customers. So far, banks have been leaders in this kind of technological advancements. E-billing entails the use of electronic systems to convey bills or invoices with payments received electronically. Yen et al. (2004) defined Electronic Bill Presentation and Payment or simply Electronic Billing as the electronic presentation of statements, bills, invoices and related information sent by a company to its customers, and corresponding payment for goods or services can also be collected.

However, Kayaga et al. (2019), observed that the bill payment and collection efficiency to support adequate service provision generally remains poor in most developing countries even after the introduced e-billing system.

Despite the introduction of e-billing to mitigate existing challenges of bill delivery efficiency and revenue collection, the system has not yielded many benefits causing primary beneficiaries to complain about the system. There is little to non-existence of a comprehensive study done on assessing adoption levels of electronic billing specifically in the water sector in Zambia. Therefore, a study to assess adoption levels of electronic billing by Lusaka Water Supply and Sanitation Company is necessary to help identify factors affecting adoption levels based on the UTAUT Model.

The limitation to this article is that the research was restricted to the 5 main branches of Lusaka water supply and Sanitation Company within Lusaka and other Water utility companies within Zambia were not included in the study.

This article is organized as follows; the article begins by outlining the background of the research which guided the study and then, the empirical literature review will be outlined. Thereafter, the article will explain the methodology used in the research followed by results and discussion of the findings. Lastly, the conclusion and recommendations will be outlined to sum up the article. 


\section{Empirical Review}

Technological advancements have brought about innovation which has changed the way companies do business. These innovations are meant to respond to dynamic changes in customer needs in a competitive environment. Recently, there has been an increase in the use of electronic billing in different business sectors. In Zambia, organizations have also become innovative by incorporating new technologies to gain efficiencies, increase competitiveness and reduce operational costs. This section, therefore, discusses the adoption levels of e-billing and establishes the factors affecting the adoption levels.

From a global perspective, research reveals that there are several factors affecting the adoption of e-billing across different sectors. Agboh (2015) suggested that innovation; motivated skilled employees and paying attention to good management strategies have a direct impact on how effective e-billing can be. However, Pai's study emphasized how Information Communication Technology (ICT) strengthens a company's internal operations but does not identify the impact it has on end-users and how adoption levels determine the success of such innovations.

Technology use in the water sector has improved over the years. Nonetheless, technology systems have been encountered with numerous risks such as data and network security risks, which have made the adoption of e-billing challenging. As a result, customers have become skeptical to use these innovations for fear of technology risks associated with data security and information on applicable models of e-billing.

According to Chimeke (2009), the successful use of technologies such as e-billing systems depends on how they are used together with the other strategies. Nevertheless, on the African continent, the critical barrier to the successful adoption of the e-billing system is poor infrastructure (Abor, 2009). Kaur, K. \& Pathak, A. (2015) observed that consumers shy away from using the Internet to aid their e-billing transactions due to poor infrastructure and failure to own mobile phone versions that support e-billing. Some scholars have alluded the failure of water utilities to adopt e-billing to costs associated with purchasing the associated equipment and networking, creation and maintenance of software, and reorganization. As a result, the successful adoption of e-billing is affected by the technological capabilities of the utility companies, as well as the effectiveness and competitiveness of the available managerial skills.

Sakala and Phiri (2019) conducted research in Zambia which was aimed at investigating the challenges of adopting the use of e-banking by customers. The results of this study revealed that the use of e-banking is dependent on the availability of e-banking information. The study further revealed that education levels have a significant influence on one's ability to use e-banking services. The other challenges affecting adoption levels of e-billing was the perceived cost in terms of accessibility to the internet and cell phones. 
Pessi (2017) affirms that in order to make the business more lucrative, organizations endeavor to reduce costs by switching to the e-billing system. Other studies indicate that e-billing minimizes operating costs by eliminating paper and data entry procedures and automating workflow such as invoice routing This is supported by the findings of Attuquayefio and Addo (2014) whose findings were that e-billing systems optimize management of operations by speeding workflow to enable payers to take advantage of early payment discounts and/or payees to provide invoices in a timely manner thus leading to improved cash flow and working capital.

Another benefit that can be derived from adopting e-billing is the timely delivery of bills as confirmed by Markovitch and Willmott (2014) who acknowledged that data in digital form is more effective, quicker and simpler to use. Implementers of e-billing agree that there exists an essential opportunity that works to enhance its effectiveness and efficiency (Boyle, 2014).

\subsection{Theoretical Framework}

The Unified Theory of Acceptance and Usage of Technology (UTAUT) was developed by Venkatesh et al. (2003). It draws reasoning from other theories of technology acceptance, namely; Technology Acceptance Model (TAM), Theory of Reasoned Action (TRA) Innovation Diffusion Theory (IDT) Theory of planned behavior (TBP) and Social Cognitive theory. The UTAUT is based on four main constructs which suggests that there are a number of factors which influence the individual decisions on the use of new technology and these factors are Performance expectancy (PE), Effort expectancy (EE), Social influence (SI) and Facilitating condition (FC).

- Performance Expectancy (PE) - The degree to which individual use will result in performance gain (perceived usefulness).

- Effort Expectancy (EE)-Referring to the ease of use of the technology.

- Social Influence (SI) - The extent that individuals believe others should use the same Technology.

- Facilitating Conditions (FC) - The perceived extent to which organization has the infrastructure to support the new technology

In addition, the model recognizes the role of demographic variables such as gender, age, experience, and the voluntariness of use which are considered as the moderator to the four constructs.

The reason for adopting the UTAUT model in this study is that it successfully integrates critical constructs from the existing ICT adoption models. This model explains $70 \%$ of the variance in intention to use a new system as compared to $40 \%$ by the Technology Acceptance Model TAM (Yen et al., 2004). More so, the UTAUT model assists in explaining the determinants of behavioral intention and user behavior of technology systems. Other than that, UTAUT is the most widely utilized Information Technology (IT) adoption based theory after Technology Acceptance Model (TAM). However, in as much as the model is 
being widely used in various technology acceptance studies, there has been no research undertaken using this model specifically in the water sector in Zambia. Figure 1 shows the adopted model used in this study.

\subsection{Conceptual Framework}

The conceptual framework of this study illustrates the relationship between independent and dependent variables of the adopted model when testing the hypothesis (Figure 2).

The independent and dependent variables developed in the conceptual framework were used to formulate the hypothesis. The following hypotheses were developed.

\section{HYPOTHESIS}

H0: Performance expectancy has no significant relationship with adoption levels of e-billing

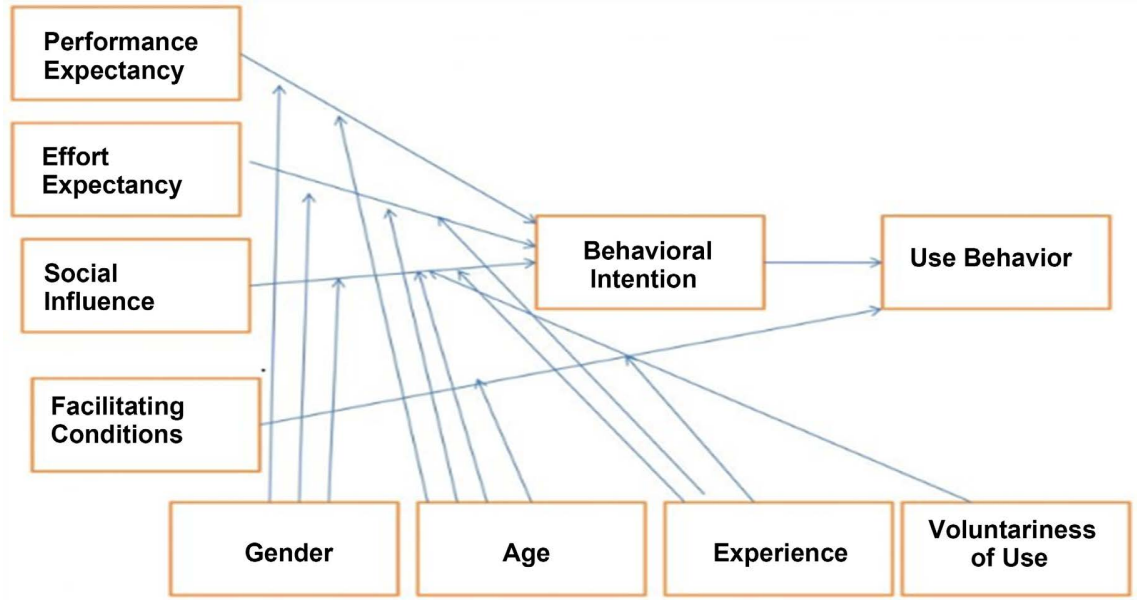

Figure 1. The unified theory of acceptance and use of technology (UTAUT) model.

\section{Conceptual framework}

INDEPENDENT VARIABLES

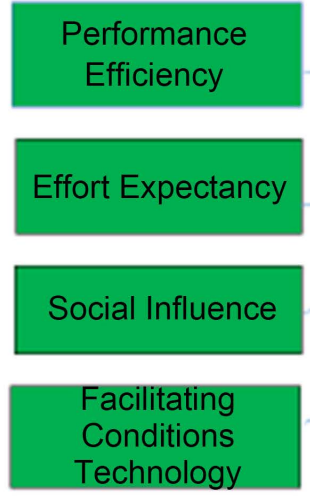

DEPENDENT VARIABLE

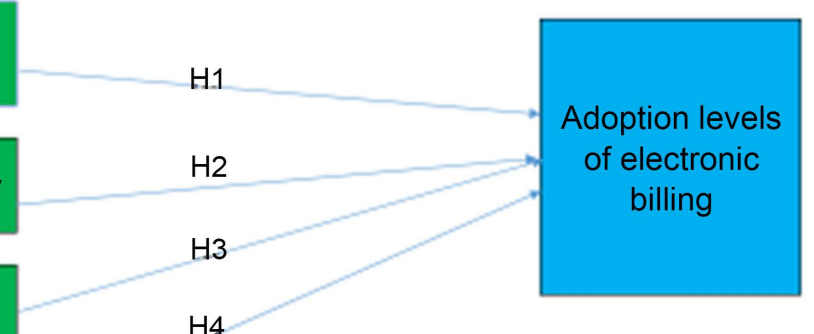

Figure 2. Conceptual framework. 
H1: Performance expectancy has a significant relationship with adoption levels of e-billing.

H0: Effort expectant has no significant relationship with adoption levels of e-billing.

H2: Effort expectant has a significant relationship with adoption levels of e-billing.

H0: Social influence has no significant relationship with adoption levels of e-billing.

H3: Social influence has a significant relationship with adoption levels of e-billing.

H0: Facilitating condition has no significant relationship with adoption levels of e-billing.

H4: Facilitating condition has a significant relationship with adoption levels of e-billing.

Related literature reviewed provided insights on the benefits of adopting and use of e-billing in various sectors like Banks, SME's and Revenue Authorities to mention but a few. Although there has been growth in the adoption of e-billing in developing countries, adoption levels have remained unknown hence the need to assess the adoption levels and usage of e-billing and identify the factors affecting adoption of the system in Zambia specifically in the water sector.

\section{Methodology}

This study used a mixed method design which comprises both qualitative and quantitative data. Quantitative research involves the use of statistical data analysis useful for analyzing relationships between dependent and independent. Whereas Qualitative research approach statistics provides an enquiry for descriptive data.

The target population for this research was the Lusaka Water Supply and Sanitation Company drawn from the five main branches which included Kabulonga, Central, Lumumba, Chelstone and Periurban within Lusaka. At the time of collecting data, the total population was 80,125 Customers (Edams Report, 2020). The sample size was determined by using the Slovin formula:

$$
n=N / 1+N\left(e^{2}\right)
$$

The Equation (1) was used to determine the sample size, where $\mathrm{n}$ is the sample size and $\mathrm{N}$ represents the population and e as the level of precision based on 5\% margin of error, It gave the sample size of 398. The study used a Likert like questionnaire to collect primary data and guided interviews. A total of 398 questionnaires were distributed but 288 completed the questionnaires, representing $72 \%$ of the response rate. Primary data was obtained from questionnaires and the interviews while secondary data was obtained from the literature reviewed from similar studies. This study adopted stratified random sampling for quantitative data and purposive sampling for qualitative data collection. According to Lindlof 
and Taylor (2005), purposive sampling is a sampling technique in which the researcher relies on his or her judgment when choosing members of the population to participate in the study.

Qualitative data from semi-structured interviews were transcribed from audio recordings into text. Thematic analysis was further used where themes were drawn from the interviews in line with the research objectives and research questions.

\section{Results and Discussion}

This chapter highlights research results of the study from the descriptive and chi square tests. Results were interpreted using SPSS which then were presented in bar charts, graphs and frequency tables for easy understanding. Figure 3 shows gender distribution of the respondents indicating that e-billing users were gender balanced with a composition of $49 \%$ female and $51 \%$ male as depicted in the bar charts.

Figure 4 shows respondents by age. The results indicate that the majority of $\mathrm{e}$ billing users were above 41 years old and least users were between 15 to 20 years old which is depicted in the graph below.

Figure 5 shows the summarized education background frequencies and percentages.

\section{Gender}

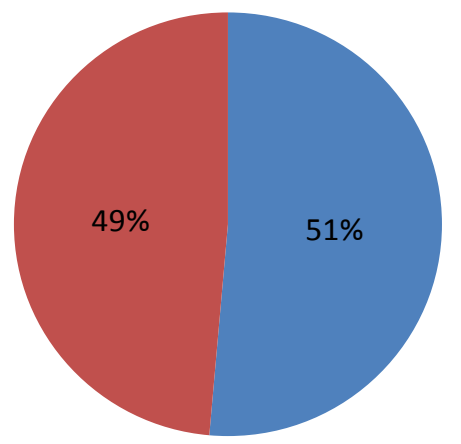

Figure 3. Gender distribution of respondents.

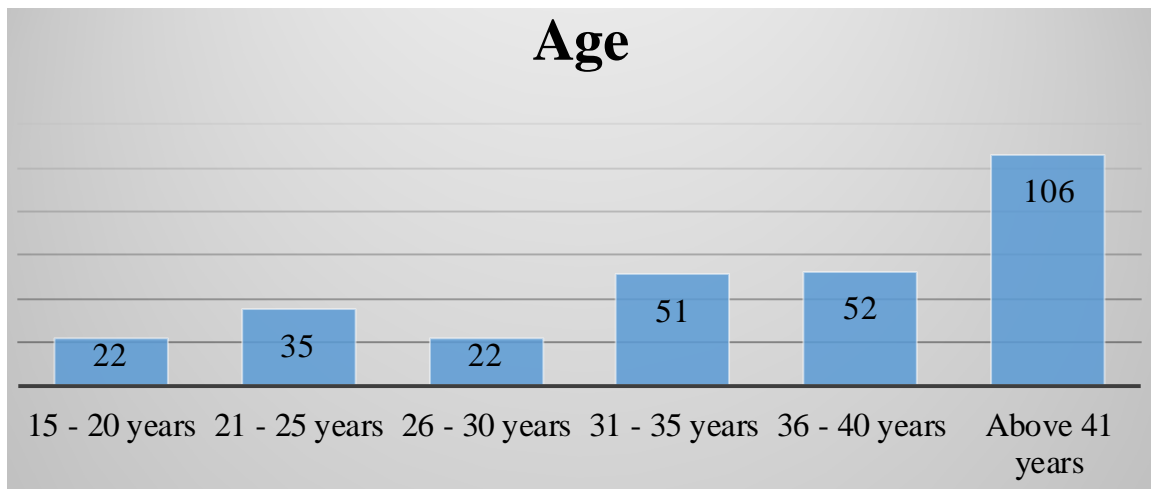

Figure 4. Age respondents. 


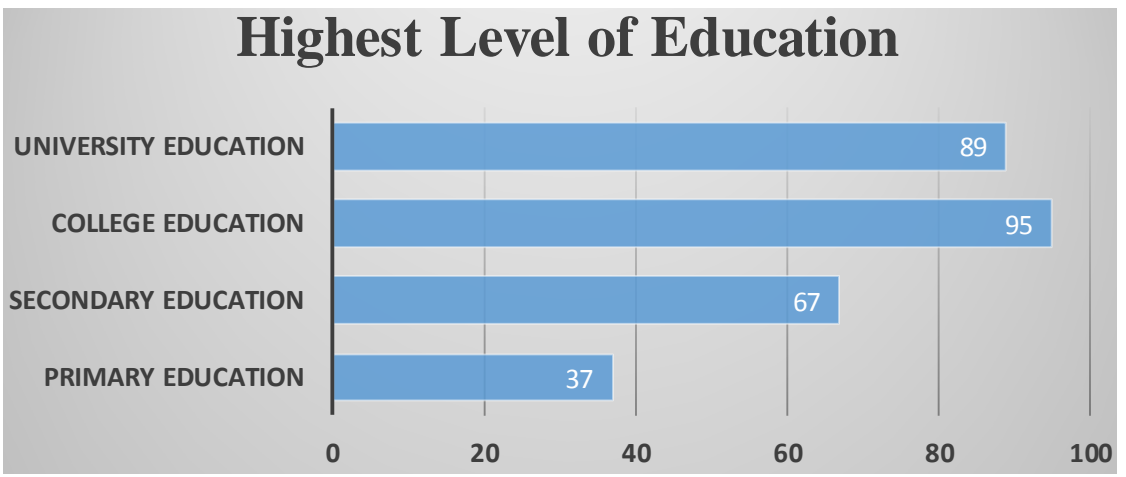

Figure 5. Level of education from SPSS analysis.

The results indicated that $67 \%$ of the respondents were educated up to grade 12 while the majority of $95 \%$ were educated up to college education and the remaining $89 \%$ were educated up to university level and the least $37 \%$ had up to Primary level. This is an indication that adoption of e-billing was high among customers who had a higher education level.

\subsection{Results Based on the Unified Theory of Technology Acceptance Model (UTAUT)}

The chi square test of independence is used to determine the significant relationship between two nominal variables. This study used the chi square as a basis of analyzing the relationship between independent and dependent variables. The hypothesis test was carried out using the $p$-value approach, which is a probability under assumption. If the $p$-value is less than 0.05 then there is strong evidence against the null hypothesis.

\subsubsection{Performance Expectancy (PE)}

Performance expectancy is one of the determinants in the intention to use technology. According to Venkatesh et al. (2003), people are likely to adopt new technologies if they believe it will be useful for them. Other studies have also indicated that PE has a positive effect on customer user intentions in adopting e-billing. Conversely, if the users' perception of e-billing is that it improves the timeliness of bill delivery, there will likely be a positive effect on their behavioral intention, as shown in Table 1 of the chi-square test statistics.

Using a Likert like questionnaire on a scale of 5, Strong disagree, disagree, Neutral, Agree, Strong agree, respondents were interrogated if e billing had improved efficiency. The results showed that $36 \%$ and $17 \%$ agreed to strongly agree respectively to the question. This implies that a good number of customers were of the view that e-billing had improved bill delivery efficiency thereby enhancing the adoption levels. The chi square test table depicts the significant relationship between performance expectancy and adoption level of e-billing based on the obtained $p$-value of 0.003 less than 0.05 . We can therefore reject the null hypothesis and conclude that there is a relationship between performance expectancy and adoption levels of e-billing. 
Table 1. Chi square test statistics.

\begin{tabular}{cccc}
\hline \multicolumn{4}{c}{ Chi-Square Tests Decision Box } \\
\hline & Value & Df & Asymp. Sig. (2-sided) \\
\hline Pearson Chi-Square & $76.822^{\mathrm{a}}$ & 9 & 0.003 \\
Likelihood Ratio & 87.826 & 9 & 0.000 \\
Linear-by-Linear Association & 0.064 & 1 & 0.800 \\
N of Valid Cases & 288 & & \\
\hline
\end{tabular}

${ }^{a} 6$ cells $(30.0 \%)$ have an expected count less than 5 . The minimum expected count is 0.61 .

\subsubsection{Effort Expectancy (EE)}

The degree of ease of use of technology has been regarded as another determinant of customer perception of technology. For instance, if e-billing is user friendly and provides convenience, it is likely that customers' attitude toward technology will be influenced positively. Huang \& Kao (2015) confirm that the assertion of effort expectancy influences consumers' attitude of use for both mandatory and voluntary usage.

In order to determine the effects of Effort Expectancy which is the ease of use of e-billing, respondents were asked if they thought e-billing was easy to use, the results showed that $63 \%$ and above found e-billing easy to use as they had above college to university level of qualification. These results mean that there is a relationship between education, effort expectancy and adoption of e-billing. Literature findings from Ajmal et al. (2017), explained that less educated people found it difficult to adopt e-billing while it was vice versa for the educated. Other support literature is from Huang and Kao (2015) who supported that effort expectancy has an influence on consumers towards the use and adoption of e-billing. Table 2 shows the chis square decision box.

The hypothesis test established a significant positive relationship between Effort Expectancy and adoption level of e-billing and $\mathrm{r}=82.822$ and $P$ value $=$ 0.021 which is less than 0.05 . This means that we can reject the null hypothesis and conclude that there is a positive relationship between effort expectancy and adoption of e-billing.

\subsubsection{Social Influence (SI)}

Social influence can also be aligned to information obtained from people. This may involve seeking advice about the pros and cons to avoid making a wrong decision. It is, therefore, one of the drivers of behaviour intentions. Sensitization among the customers was one way of increasing social influence in the adoption of e-billing. Using a questionnaire customers were interrogated on whether they thought people who are influential to them and people who are important to them should adopt e-billing system, the results showed that $43 \%$ agreed while $40 \%$ remained neutral. The results indicated that there is a moderate social influence over adoption of e-billing. The results mean that social influence plays a role in optimizing adoption levels of new technologies, below are the results of the chi square test shown in Table 3. 
Table 2. Chi square test statistics.

\begin{tabular}{cccc}
\hline \multicolumn{4}{c}{ Chi-Square Tests Decision Box } \\
\hline Value & Df & Asump. Sig. (2-sided) \\
\hline Pearson Chi-Square & $82.822^{\mathrm{a}}$ & 9 & 0.021 \\
Likelihood Ratio & 87.826 & 9 & 0.000 \\
Linear-by-Linear Association & 0.064 & 1 & 0.800 \\
N of Valid Cases & 288 & & \\
\hline
\end{tabular}

${ }^{\mathrm{a}} 6$ cells $(30.0 \%)$ have an expected count of less than 5 . The minimum expected count is 0.61 .

Table 3. Chi square test statistics.

\begin{tabular}{cccc}
\hline \multicolumn{4}{c}{ Chi-Square Tests Decision Box } \\
\hline & Value & Df & Asymp. Sig. (2-sided) \\
\hline Pearson Chi-Square & $77.622^{\mathrm{a}}$ & 9 & 0.021 \\
Likelihood Ratio & 87.826 & 9 & 0.000 \\
Linear-by-Linear Association & 0.064 & 1 & 0.800 \\
N of Valid Cases & 288 & & \\
\hline
\end{tabular}

${ }^{\mathrm{a}} 6$ cells $(30.0 \%)$ have an expected count less than 5 . The minimum expected count is 0.61 .

The hypothesis test established that there is significant positive relationship between Social Influence and adoption level of e-billing $\mathrm{r}=77.622$ and $P$-value $=$ 0.021 which is less than 0.05 . These findings resonate with Ndayizigamiye's (2012) who indicated that social influence has an impact on the adoption level of e-billing. Based on the $p$ value which is less than 0.05 we can reject the null hypothesis and conclude that there relationship between social influence and adoption of e billing.

\subsubsection{Facilitating Condition (FC)}

Facilitating conditions refer to the degree that the organizations' infrastructure supports the use of the e-billing system. Emeka et al. (2019) in his research indicate that facilitating conditions have a significant impact on the level of adoption of technology and its usage. Using a questionnaire four questions, were asked 1) I have effective internet access to receive e-bills, 2) I have the knowledge necessary to use and access e-billing 3) I have the skill to use e-billing, and 4) Electronic platforms have numerous services which are offered from the branches. The results indicated that $18.06 \%$ strongly disagreed, 46.88 disagreed, $14.93 \%$ were neutral $16.32 \%$ agreed and $3.82 \%$ strongly agreed. These results indicate that the majority of the customers could not access their e-bills via emails due to non-availability of internet access which can be attributed to the customers not having smart phones or computers especially those from Periurban areas and the elderly customers. A hypothesis test done to establish the relationship between 
Table 4. Chi square test statistics.

\begin{tabular}{cccc}
\hline \multicolumn{4}{c}{ Chi-Square Tests } \\
\\
\hline Value & Df & Asump. Sig. (2-sided) \\
\hline Pearson Chi-Square & $82.390^{\mathrm{a}}$ & 12 & 0.000 \\
Likelihood Ratio & 81.167 & 12 & 0.000 \\
N of Valid Cases & 288 & & \\
\hline
\end{tabular}

a 5 cells $(25.0 \%)$ have an expected count less than 5 . The minimum expected count is 1.41 .

facilitating condition and adoption levels of e-billing showed that there is a relationship between Facilitating condition and adoption level of e-billing as $\mathrm{r}=$ 82.390 and $p$ value $=0.000$ which is less than 0.05 as shown in Table 4 .

This implies that limited access to internet and mobile phones was an impediment to the adoption levels of e-billing among customers. Therefore, we reject the null hypothesis and conclude that there is a positive significant relationship between facilitating condition and adoption level of e-billing.

\subsubsection{Summary of the Hypothesis Test}

A Pearson correlation was utilized to determine whether the independent \& dependent variables are significantly related. The $\mathrm{H} 0$ was rejected as the $P$-Values in all the variables is $<0.05$. Therefore, based on these results indicated on all the four variables tested, it was concluded that there was a significant positive relationship between independent (PE, EF, SI \& FC), and dependent variables (Adoption levels of e-billing).

\section{Conclusion}

The study concluded that despite the majority of respondents indicating that adoption of e-billing is challenging, respondents were of the view that e-billing adoption has ensured that bills are now received on time, more convenient than paper bills and has increased efficiency in revenue collection at LWSC. It can therefore be argued that the adoption of an e-billing has many benefits to both the LWSSC and the consumers as it is based on the aspect that it speeds up productivity.

The study established that lack of access to the internet was among the key factors impeding the adoption of e-billing. These results mean that the majority of the customers could not access their e-bills via emails due to non-availability of internet access, which can be attributed to the customers not having smart phones or computers, especially those from the Periurban area and the elderly customers.

It was established that e-billing does not provide any feedback as to whether the customer has received the bill via short messaging system, email or not. Further the study concludes that less educated people found the e-billing system not user friendly especially the payment apps. It was therefore paramount that 
LWSSC introduced userfriendly applications to cater to less educated people and the elderly.

\section{Recommendations}

LWSSC Management should enhance sensitization on the use of e-billing to its customers as this will improve adoption levels. Secondly, the providers and top management should find a tailor-made feedback mechanism process where customers can acknowledge receiving their bills, reminders and notices. There is also a need to develop a new app which is more users friendly that will enable customers to log in complaints, check balances and check for their statements without visiting Physical service centers.

Lastly there is need to build capacity and train the IT staff as LWSSC is heavily relying on system developers to resolve arising complaints of e-billing like duplicate e-payments and transactions not reflecting on the statements.

\section{Limitations}

The findings of this study cannot be generalized as it is a customer based research and was restricted to selected branches in one of the water utility companies in Zambia.

This study was focused on 5 Branches leaving out other districts like Chongwe, Kafue Luangwa and Chirundu which would have given a broader view of adoption levels of e-billing from different districts.

Future studies should be conducted on customer perception of e-billing which would cover remote satellite areas which were left out I this study.

\section{Acknowledgements}

I appreciate the valuable support of all the respondents who took part in this study.

\section{Conflicts of Interest}

The authors declare no conflict of interest in the publication of this paper.

\section{References}

Abor, J. A. (2009). Technological Innovations and Banking in Ghana: An Evaluation of Customers' Perceptions. University of Ghana.

Agboh, D. K. (2015). Drivers and Challenges of ICT Adoption by SMES in Accra Metropolis, Ghana. Journal of Technology Research, 6, 1-16.

Ajmal, F., Yasin, N. M., \& Norman, A. A. (2017). Critical Success Factors Influencing E-Commerce Adoption in SMEs: A Review and Model. International Journal of Advanced and Applied Sciences, 4, 159-172. https://doi.org/10.21833/ijaas.2017.07.023

Attuquayefio, S. N., \& Addo, H. (2014). Using the UTAUT Model to Analyze Students' ICT Adoption. International Journal of Education and Development using Information and Communication Technology, 10, 75-86. 
Boyle, C. E. (2014). Adapting to Change: Water Utility Financial Practices in the Early Twenty-First Century. Journal of American Water Works Association, 106, E1-E9. https://doi.org/10.5942/jawwa.2014.106.0015

Chimeke, S. (2009). The Adoption of Internet Banking in Nigeria: An Empirical Investigation. Journal of Internet Banking and Commerce, 11, 1-10.

Edams Report (2020). Lusaka Water Supply and Sanitation Company. Complaint Resolution Monthly Report.

Emeka, E. E., Abba, G. O. A., \& Fatokum, G. F. (2019). Impact of Electronic Banking on Financial Inclusion in Nigeria. American Journal of Industrial and Business Management, 9, 1409-1422. https://doi.org/10.4236/ajibm.2019.96092

Huang, C.-Y., \& Kao, Y.-S. (2015). UTAUT2 Based Predictions of Factors Influencing the Technology Acceptance of Phablets by DNP. Mathematical Problems in Engineering, 2015, Article ID: 603747. https://doi.org/10.1155/2015/603747

Kaur, K., \& Pathak, A. (2015). E-Payment System on E-Commerce in India. International Journal of Engineering Research and Applications, 5, 79-87.

Kayaga, S., Richard, F., \& Samson, K. (2019). Bill Payment Behaviour in Urban Water Services: Empirical Data from Uganda. Journal of Water Supply: Research and Technology-Aqua (2004), 53, 339-349. https://doi.org/10.2166/aqua.2004.0027

Lindlof, M., \& Taylor, K. (2005). Qualitative Communication Research Methods (2nd ed.). Sage.

Markovitch, S., \& Wilmot, P. (2014). Accelerating the Digitalization of Business Processes (pp. 1-4). Mckinsey-Corporate Finance Business Practice.

Ndayizigamiye, P. (2012). Adoption of E-Commerce by Small, Medium and Micro Enterprises in Pietermaritzburg and Durban (205 p.). https://researchspace.ukzn.ac.za/handle/10413/9682

Pessi, B. (2017). The Impact of Implementation of Electronic Purchase Invoice System on a Company on the Example of Hahle Group. Tallinn University of Technology.

Poel, K., Marneffe, W., \& Vanlaer, W. (2016). Assessing Electronic Invoicing Potential for Private Sector Firms in Belgium. The International Journal of Digital Accounting Research, 16, 1-34. https://doi.org/10.4192/1577-8517-v16 1

Sakala, L., \& Phiri, J. (2019). Factors Affecting Adoption and Use of Mobile Banking Services in Zambia Based on TAM Model. Open Journal of Business Management, 7, 1380-1394. http://www.scirp.org/journal/ojbm https://doi.org/10.4236/ojbm.2019.73095

Venkatesh, V., Morris, G. B., \& Davis, F. D. (2003). User Acceptance of Information Technology: Toward a Unified View. MIS Quarterly, 27, 425-478. https://doi.org/10.2307/30036540

Yen, J. et al. (2004). Electronic Bill Presentment and Payment (EBPP): The Case at Hong Kong Shanghai Commercial (HSBC) Bank. International Journal of Electronic Business Management, 2, 1-13. 